This item was submitted to Loughborough's Research Repository by the author.

Items in Figshare are protected by copyright, with all rights reserved, unless otherwise indicated.

\title{
Physical activity and rural young people's sense of place
}

PLEASE CITE THE PUBLISHED VERSION

http://dx.doi.org/10.1080/14733280902798894

PUBLISHER

(C) Taylor \& Francis

VERSION

AM (Accepted Manuscript)

LICENCE

CC BY-NC-ND 4.0

REPOSITORY RECORD

Lee, Jessica, and Rebecca Abbott. 2019. "Physical Activity and Rural Young People's Sense of Place". figshare. https://hdl.handle.net/2134/5937. 
This item was submitted to Loughborough's Institutional Repository (https://dspace.lboro.ac.uk/) by the author and is made available under the following Creative Commons Licence conditions.

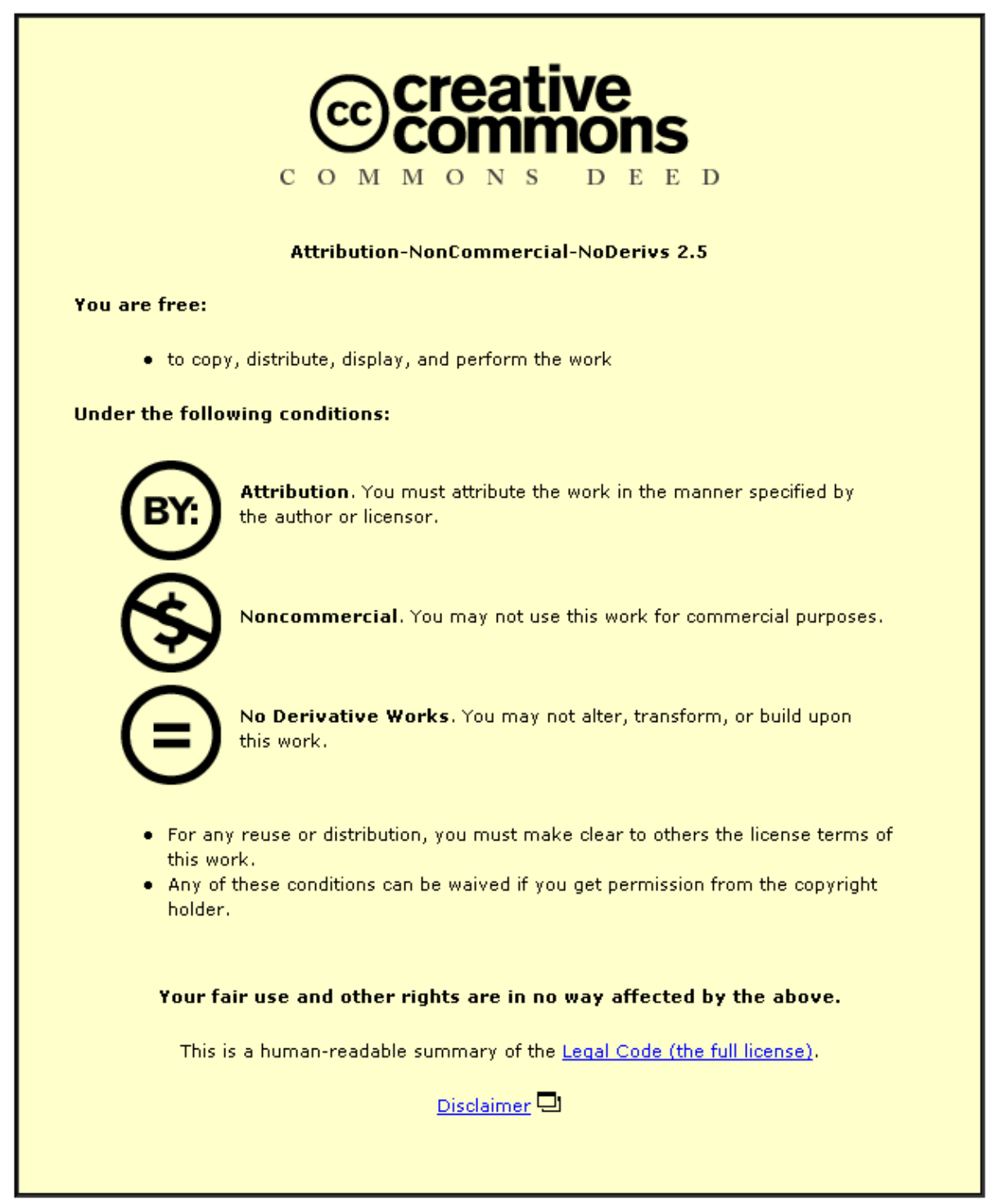

For the full text of this licence, please go to: http://creativecommons.org/licenses/by-nc-nd/2.5/ 


\section{Physical activity and rural young people's sense of place}

Jessica Lee $^{\mathrm{a}}$ and Rebecca Abbott ${ }^{\mathrm{b}}$

${ }^{\mathrm{a} S c h o o l ~ o f ~ S p o r t ~ a n d ~ E x e r c i s e ~ S c i e n c e s, ~ L o u g h b o r o u g h ~ U n i v e r s i t y, ~ L e i c e s t e r s h i r e, ~ L E 11 ~ 3 T U, ~ U K ~}$

bschool of Human Movement Studies, The University of Queensland, Brisbane, QLD 4072, Australia

\section{Corresponding author:}

Dr Jessica Lee

School of Sport and Exercise Sciences

Loughborough University

Leicestershire

LE11 3TU

UK

Phone: $+44(0) 1509223275$

Fax: +44 (0)1509 226301

Email: j.lee2@lboro.ac.uk

Paper published in Children’s Geographies, 7 (2), 191-208. 
Physical activity and rural young people's sense of place 
Rural young people and physical activity

\section{Abstract}

This paper explores rural young people’s perceptions of their local environments in relation to their experiences with physical activities through the use of visual methodologies. The main findings from map, photo and interview data from thirteen rural young Australians included the importance of friends, family, and gender structures which are discussed in relation to developing a sense of place and how this shapes their experience in physical activities. The findings highlight the importance of sociocultural issues and raises questions regarding measuring physical activity prompting further qualitative research to inform sustainable and equitable physical activity promotion initiatives for rural young people.

Keywords: rural young people, physical activity, place, maps, photos 
Rural young people and physical activity

\section{Introduction}

The current study was interested in exploring the impact of social and physical environments on rural young people’s perceptions of, and participation in, physical activities. Research on rural young people's experiences of physical activity is diverse, and somewhat conflicting. An Australian study of physical activity and nutrition among Central Queensland young people reported that 'rural youth were significantly less likely to be physically active than their town and city counterparts' (Mummery, Schofield, Abt, and Soper, 2000, p. 318). Similarly, Gordon and Caltabiano (1996) found that North Queensland rural young people reported less leisure time physical activity than urban young people. The rural young people however did report greater satisfaction with their leisure time compared to the urban young people and it was concluded that perhaps 'rural youth learn to make do with available leisure options’ (Gordon and Caltabiano, 1996, p. 41). In contrast, sport is often described as the 'social cement' that holds rural communities together (Mugford, 2001) and indeed, some Australian statistics show that more rural young people participate in organised sports than their urban counterparts (Australian Bureau of Statistics [ABS], 2000; 2003). Savage and Scott (1998) reported that physical activity patterns were similar between rural and urban young people in Indiana (USA). Giddings and Yarwood (2005) noted that English rural boys and girls used the same leisure spaces in different ways with boys playing more sports and organised games in groups while girls' activities were less formal and based around meeting and talking. In general however, Tonts (2005) reports that research on rural sports (and physical activities) has focussed on questions associated with infrastructure provision, facilities management, physical activity, and health promotion, leaving social dimensions rarely studied. One such dimension that has been little researched in relation to physical activity and rurality is that of place.

Meanings of place and how place emerges and evolves from undifferentiated space have become increasingly popular themes in scholarly research (Stokowski, 2002). Researchers in this area have come to understand places as more than simply geographic sites but as fluid, changeable, dynamic 
Rural young people and physical activity

contexts of social interaction and memory (Stokowski, 2002, p. 369). Place as a sociocultural construct has been researched in relation to its impact on various aspects of rural young people's lives. Australian and international studies tend to concur that rural young people's experiences of place are diverse and strongly influenced by their own interpretations of their social and cultural environments. Vanderbeck and Morse Dunkley (2003) in exploring the importance of place in identity formation for rural young people in northern Vermont (USA) suggested that young people's own interpretations of popular public discourses or narratives of rurality influenced the shaping of their social identities. As such, it was concluded that rural young people living in the same location may have different views of the world or sense of place.

A study of rural New Zealand young people’s meanings and understandings of socio-spatial processes of their environments reported similar findings (Nairn, Panelli, and McCormack, 2003) where rural young people's views of their environments were diverse and 'challenge deterministic accounts of young people as automatically excluded from public space' (p. 37). In their interviews and discussions of photos, the New Zealand rural young people spoke about inclusion and exclusion based on cultural understandings of their socio-spatial environments (Nairn et al., 2003). Importantly, Giddings and Yarwood (2005) suggested that it would be 'wrong' (p. 111) to consider rural young people as marginalised or deprived based only on their rural location. Indeed, very few of the English rural young people they studied regarded themselves in this way as they had formed their own identities in relation to their sense of place (Giddings and Yarwood, 2005).

An inclusive way of exploring young people's perceptions of their local environments that privileges young people’s own perspectives is to use maps and photographs. Hume, Salmon and Ball (2005) had Australian young people draw maps and photograph places in their environments that were important to them. Opportunities for physical activity arose as an important theme in the maps and photographs as did social spaces within the family home. There was not a strong 
Rural young people and physical activity

relationship between young people’s perceived environments as measured by maps and actual participation in physical activity (Hume et al., 2005). This could perhaps be due to the discrepancy between availability and accessibility of leisure and physical activity facilities. Malone and Hasluck (1998) explored young people’s perceptions of social space with maps and photographs and found that although a large leisure centre was a feature of the local community, less than one in ten young people actually played a sport. The young people themselves expressed that while the well equipped sporting facility was apparently available for their use, they could not afford the entry fee, they had to be a member of a team before they could enter (eliminating the opportunity for recreational games), and there were no facilities for young people to socialise (Malone and Hasluck, 1998). The use of maps and photographs has been particularly useful in these two studies (Hume et al., 2005; Malone and Hasluck, 1998) to explore young people’s perceptions of their environments and experiences in physical activity. In another study, Ross (2007) reported on children’s negotiations of their localities through the use of children's own photography focussing on the regular routine of the journey to school. The photographs revealed children's everyday geographies and highlighted significant 'aspects that may have otherwise been overlooked, un-thought of or trivialised' (Ross, 2007, p. 382).

The aim of this paper is to explore a sample of rural young people's perceptions of their local environments, both social and geographical and to examine how they impact on their experiences with physical activities. As with previous research, young people's maps and photographs along with interviews were employed as a means of 'looking up’ and gaining young people’s own perspectives of their localities in their every day lives in relation to their experiences in physical activities. 
Rural young people and physical activity

\section{Research method}

\section{Participants and locations}

Participants formed a sub-sample of young people living in rural Queensland who were part of the Life Activity Project; a qualitative longitudinal study funded by the Australian Research Council (ARC). The Life Activity Project (LAP) was established as a response to the decreasing numbers of young people participating in sports and physical activities, as reported in epidemiological studies. The study has explored the place and meaning of physical activity to young people in a variety of geographic locations across Eastern states in Australia. Data used in this paper were derived from two semi-structured interviews (maps and photos) that were conducted in 2002 and 2003. Further information on the visual methods is included in the next section.

The cohort of 13 rural young people whose data are reported in this paper was recruited from two different schools. The first was Greenvalley High ${ }^{1}$, a secondary school (years 8-12) in a regional town in Queensland located approximately 100 kilometres from a major city. The town had a population of around 1700 people with agriculture being the main industry with small farms and acreages. The unemployment rate was high (approximately 11\%) with limited opportunities for part-time work. Although physical distance was not great, public transport to city and regional centres was lacking which resulted in a sense of physical isolation. Greenvalley High had approximately 700 students enrolled in years 8-12 and claimed to have 'Good quality but limited school sporting facilities' (cited on school website). The community did have a large indoor sports complex, however it had been closed down due to lack of use by local sporting organisations such as the community netball competition which had been discontinued due to lack of interest. Clubs and facilities available in the town included a junior rugby league club, summer junior swimming club (25-metre pool), golf course, and a touch football competition. Eight students across two year levels, who were in year eight (first year of secondary school) and year 10 (last year of compulsory schooling) at the time of recruitment participated in the longitudinal project. At the time of the map 
Rural young people and physical activity

and photo interviews the Greenvalley High participants were aged between 16 and 18 years (five females, three males).

A further five young people from a school of distance education were part of the cohort. They were two males and one female who were in year seven at the time of recruitment, one male who was in year six, and one male who was in year eight. Distance education is a common option in Australia for geographically remote students where lessons and assessment are conducted via mail, telephone, and audiotape with an approved adult (usually the mother) as a home tutor. The five participants lived in four different locations ranging from 250 to 600 kilometres from the capital city. One lived in a small town while the other four lived on more remote properties between 20 and 60 kilometres from the nearest town. They were aged between 12 and 14 at the time of the map and photo interviews.

A reference to the young people's socioeconomic status and ethnicity is warranted here given the associations of these variables with participation in physical activities demonstrated in epidemiological studies. All of the participants were of working class background from single income families with some relying on government benefits. One young man lived on his family run sheep and cattle property which had been severely effected by drought. Another young man's family, while relying on the income of their crop farm (i.e. neither parent worked outside the property), had greater economic and social flexibility than the other participants however, this appeared to be largely due to close proximity of extended family and long standing knowledge of the local area rather than economic prosperity. All of the participants were of a 'white' AngloAustralian background. As such, this was a reasonably homogenous group in terms of socioeconomic status and ethnicity. On the surface therefore, it would be supposed that they would be subject to the lack of opportunities and facilities that are largely reported as being the 'plight' of rural young people and the reason for poorer health as stated earlier. As will be highlighted in the 
Rural young people and physical activity

results and discussion however, the use of visual methods revealed that the rural young people felt that their diverse experiences with physical activity were shaped more by social relationships than physical location and access to facilities.

\section{Visual methods}

Researchers have emphasised that children's perceptions and uses of space may be different from those of adults' (Matthews and Limb, 1999; Tucker, 2003) which highlights the need to 'look up’ from young people’s own perspectives (Tucker, 2003) and investigate the environment as children see it. Using visual methods to supplement interview data can allow young people to express themselves in different ways and thus, can be useful in building a picture of their lives and culture from a range of perspectives (Morrow, 2001). This method of data collection allows young people to have some authority over the content of interviews as they have selected the images that represent their own lives and have the opportunity to interpret and represent their own meanings. Clark (1999) used the term autodriving to describe the situation where an interview is driven by the informant; a process that helps ensure that the interview includes topics relevant to the child. In using photographs to explore children’s views of their social worlds, Orellana (1999) highlighted the importance of children's own meanings of the photos to contextualise the researcher's analyses. Using visual methods also assists in forming an understanding of how the spaces within physical environments become places that are personally significant in different ways for different young people (Orellana, 1999).

Participants were asked to draw their own maps/pictures of their local area including their house (and property) and any other places in their area that they visited or were important to them (examples provided were shops, library, and neighbours). They did not have to be an accurate representation of distances or sizes of places. It was specified that long stretches of road between 
Rural young people and physical activity

locations did not have to be included and that they should note distances between their home and places they drew on their maps.

The Greenvalley participants drew their maps in the interview situation following questions about describing their local areas and where they spent their time. Distance education participants were sent instructions in the mail with an example map and were asked to draw their maps on A3 paper and send them to the researcher. Once the maps were returned, a phone interview was arranged to ask the scheduled questions and specific questions about their maps. While Greenvalley participants were not given an example map, they were given instructions to include important places and places that they go regularly. The written material sent to Distance Education students had similar instructions and the example map was produced by the researcher who drew a map of her own local area following the same instructions. As the researcher lived in the city suburbs it was not expected to resemble the maps produced by the young people and was not deemed to be suggestive of the types of places to include.

Participants also took photos using 24-exposure disposable cameras. They were asked to take photos of the things that they do during a normal day and any people or places that were important to them. When the photos had been developed they were discussed in an interview where participants were asked what each photo was of and why they had taken it. Some scheduled questions followed including asking them to nominate their favourite photos and how they felt about having their own photo taken. Twelve of the thirteen interviews based on the photographs were conducted face-to-face with one conducted via telephone while both interviewer and interviewee looked at their own copies of the photos. 
Rural young people and physical activity

\section{Data analysis}

Following the method demonstrated by Hume et al. (2005), the maps and photos were analysed for themes and for the frequency with which particular objects and locations appeared. As some of the rural young people included locations such as shops and sports grounds on their maps that were not particularly relevant to their own lives, the interview data relating to their maps was used to identify and code only the locations that the participant themselves considered important. Therefore, not all locations that participants drew on their maps were coded into themes, only the ones that they identified as significant.

\section{Results and Discussion}

Of the 13 participants, 12 drew maps and took photos generating a total of 12 maps and 313 photographs. After coding for content (map locations, photo subjects), a total of 5 themes from the maps and 14 themes from the photographs were identified and are presented in Tables 1 and 2. 
Rural young people and physical activity

Table 1. Themes emerging from photos.

\begin{tabular}{ll}
\hline Theme & Total Photos \\
\hline School & $32^{@}$ \\
Chores & 23 \\
Self & 20 \\
Scenery & 11 \\
Pets (playing, walking, on their own) & 40 \\
Friends & 30 \\
Family & 44 \\
Self eating (prep food) & 6 \\
Home & 10 \\
Work & 3 \\
PA/sport & 38 \\
Recreational activities (play, not PA) & 15 \\
Watch TV, video/computer games & 3 \\
Other & $27^{*}$ \\
\hline
\end{tabular}

Note. A total of five photos from three participants were too dark or unclear to distinguish their subjects.

@ 24 photos within this theme were considered as 'at school with friends' and are therefore analysed in addition to the 30 categorised in the friends theme.

* 'Other' category includes riding equipment, trophies and awards, photos of other meaningful photos, horse feed, shopping, volunteer work, sleeping, tractors.

Table 2. Themes emerging from maps.

\begin{tabular}{lc}
\hline Theme & Total Map locations \\
\hline Friends/family & 25 \\
Sport/PA & 14 \\
School/work & 13 \\
Social & 8 \\
Other & $6^{*}$
\end{tabular}

Note. Many incidental locations were recorded on maps. Only locations that were identified as important by the participants were coded into themes.

* 'Other' locations included the library, pet food and grocery shops, Corvette car sales, and a woodwork workshop. 
Rural young people and physical activity

Four of the themes from the photographs coincided with themes from the maps. The major themes identified in both the maps and photos were family, friends, sport, and physical activity. There was also large overlap across these themes where friends and family were often depicted in relation to sport or physical activity contexts, both in maps and photos. A discussion of these themes and the interplay between them will be presented in the following sections. The tables represent a more quantitative approach to the analysis of the photos and maps and can sometimes distort the more qualitative importance of some categories. For example, in Table 1, Pets is identified as the most common theme with 40 photos relating to walking, caring for, and showing pets (dogs and horses). While this category has a large number of photos, it is not an accurate representation of the spread across all participants. Two female participants contributed 29 photos to this category between them, and four others contributed the remaining 11. It is therefore not considered a major theme that was common amongst the participants. The School theme also featured prominently with a total of 32 photos. Within this theme however, 24 photos were coded as 'at school with friends' and were therefore considered within the friends theme which already accounted for 30 photos not within a school context. It is acknowledged that schools were considered sites for socialising and participating in physical activities and as such, are discussed further in relation to friends, sport, and recreational physical activities. The interview data are used to contextualise the more quantitative analysis of the themes and clarifies the importance of the themes within the young people's lives.

\section{Family, friends, sport and physical activities in the lives of rural young people}

It was evident in both the maps and photographs that the rural young people’s families and friends were an important part of the social fabric in their lives. The photographs and maps and particularly the explanations of them in the interviews revealed the intense importance of family relationships particularly for some of the young women. 
Rural young people and physical activity

My family, definitely my family. They're my number one priority at the moment (Greenvalley High female aged 18, Map interview).

Photo 21 of my parents is my favourite... 'cause you only have one set of parents, they're mine (Greenvalley High female aged 16, Photo interview).

A map from a Greenvalley High participant presented in Figure 1 demonstrates her depiction of her grandmother's and friends' houses in relation to her own. The photography exercise provided a forum for these young people to express the importance of their families that had not been exposed in earlier interviews. 


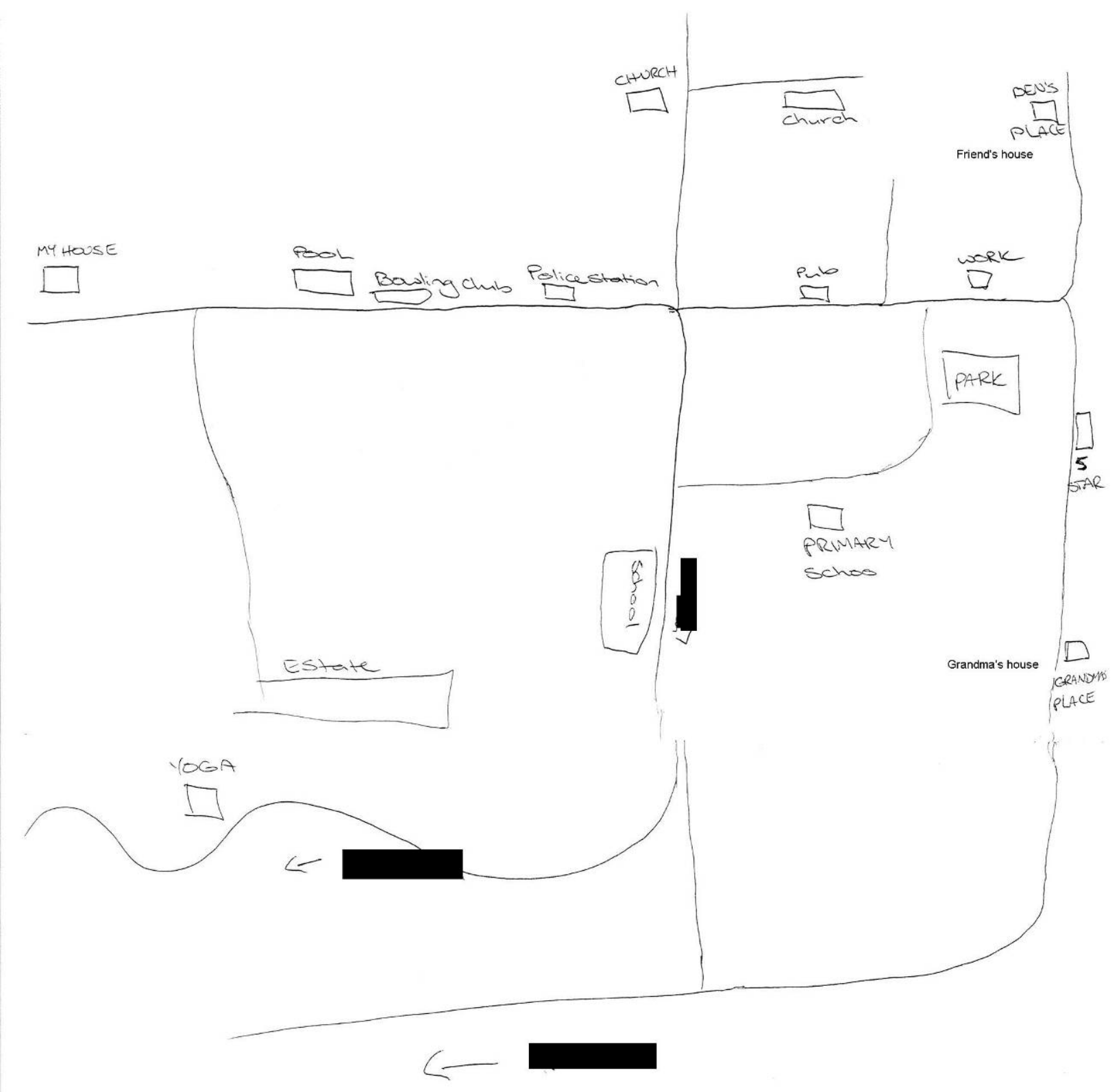

Figure 1. Greenvalley High participant map (female aged 18) with her grandmother's and friend's houses marked in relation to her own home.

Physical activity was the second most common theme in both the maps and photos, however it was more prominent in the photos than the maps. There was a distinction between sites and contexts of sports and recreational physical activities. For example, the young man’s map in Figure 2 included three sites where he participated in sports: the pool, the golf course, and the recreational grounds where he played touch football. 


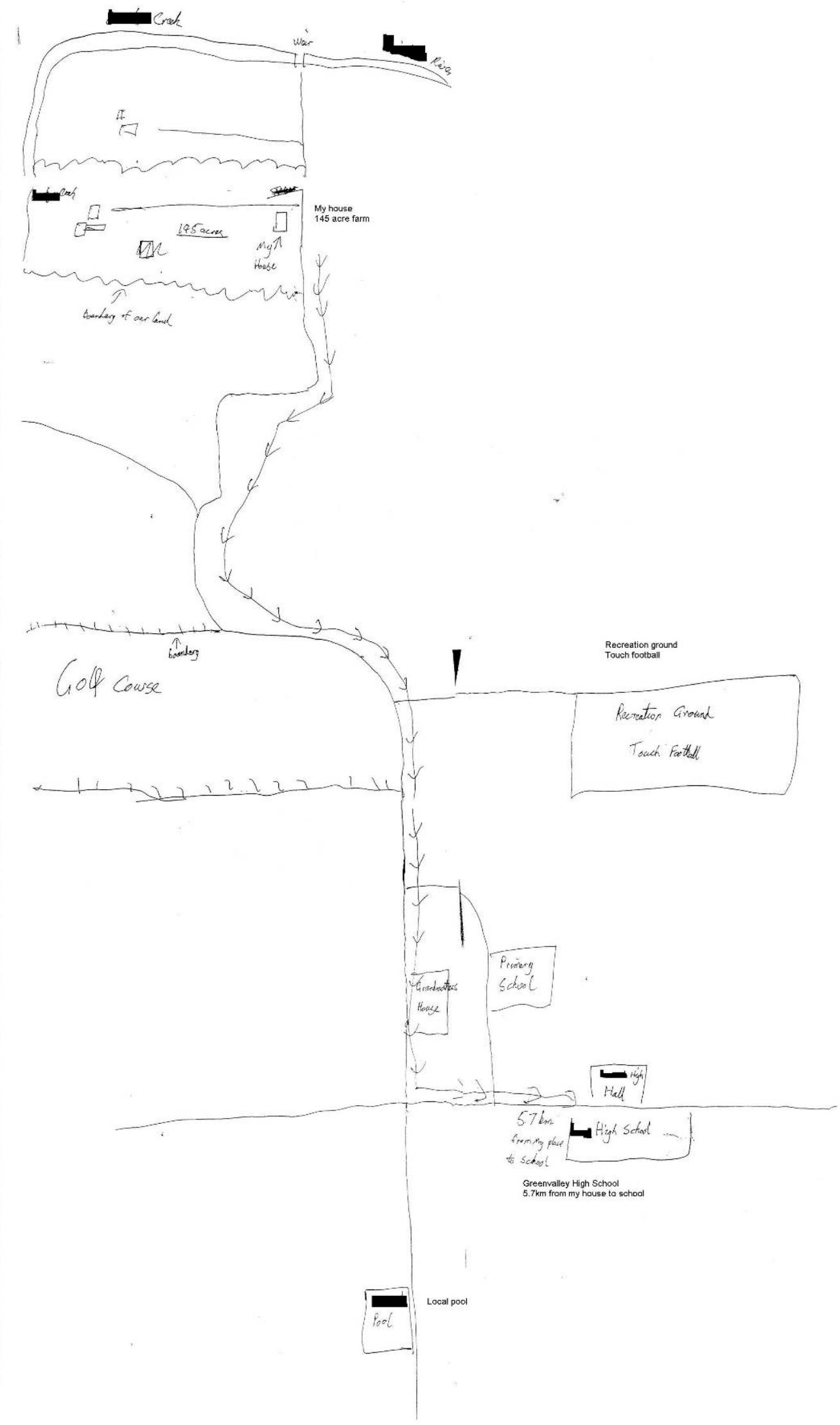

Figure 2. Greenvalley High Participant map (male aged 16) demonstrating his family property, venues where he participates in organised sports in Greenvalley, and his grandparents' house. 
Another young man drew on his map two sites around his home where he participated in recreational activities with his brothers (cricket nets and oval) as well as the cricket club in the regional centre. One young woman's map and photos depicted the primary school where she played recreational tennis with friends. The school was represented by some as a site for both recreational and organised physical activities in the photographs. One distance education participant included photos of himself and friends participating in a school swimming lesson and a Greenvalley High participant had a number of photos of himself with his school volleyball team at an inter-school competition. In terms of recreational activities, one young woman took photos of her friend playing tennis at the local primary school courts. The school was only one site for physical activities however, with the home and sporting clubs being more commonly represented sites in the photographs.

While there was a mix of recreational and organised physical activities represented in the maps and photos, instances of recreational physical activities were more common than organised physical activities such as sports. Sporting venues were drawn on maps and photographed including a golf course, touch football field, swimming pool, cricket club, and dressage competitions, and one young man included the State Emergency Services (SES) shed where he participated in organised physical training activities. Sites for recreational physical activities included a walking track, a ropes course, home cricket nets, a home tennis court, a dam for kayaking, home table tennis, a local school tennis court, a horse riding trail, and a home basketball hoop. It is also noteworthy that the young men were more likely to include venues for physical activity on their maps and in photos than were the young women.

Physical labour was represented under other themes such as 'chores' (23 photos) and 'work' (3 photos). Representations of physical labour were more common among the young men, some of 
Rural young people and physical activity

whom photographed farming machinery like tractors and described their relevance in interviews. There were also photos supplied by some young men of themselves actually participating in physical labour - chopping fire wood, digging a drainage trench, and throwing blocks of cattle nutrients from the back of a truck.

Well this is a posed photo of me on the tractor to show you what we do, or what I do. We use this little tractor to push little sucker bushes and so that's like re-growth control I guess... at the time of this photo we were pushing nearly every day, three hours each. [Interviewer: So it is something that you and your brother and sister all do?] Yeah well not my sister, she doesn't drive the tractors... mainly because I suppose it's sort of rough, it's a boy thing (Distance education male, aged 14).

Chopping the wood... like hot water would last about two and a half days so I'd chop a big load and it'd last all week (Distance education male, aged 14).

Two young women represented physical labour in their photos. One young woman who worked on a turf farm described the photo depicting herself before work in her work clothes as follows, "Oh that's me going to work on the turf farm. I look like a boy [laughing].” (Greenvalley High female, aged 16).

Another young woman's photos of her stables and riding equipment prompted her comments on the types of daily physical tasks involved in the upkeep and training of a stable of equestrian horses.

The impact of friends and family on physical activity and sport participation was explicitly revealed throughout the maps and photos. There were a number of photos coded in both the friends/family theme and the physical activity theme. Such photos included those of friends participating in 
Rural young people and physical activity

physical activities, friends in a sport context but not actually participating, and participating in physical activity with family members. Examples of these instances are participating in recreational physical activities with siblings (Figure 3) and a posed shot of a participant and his friends at the swimming pool before a training session (Figure 4). Most of the photographs coded in the physical activity theme included friends or family members, which highlights the social nature of the rural young people’s participation in both recreational and organised physical activities. The young people’s own explanations of their maps and photos highlighted the importance of family and friends as co-participants and identified sporting opportunities also as a chance to make friends.

That's Dan's house, he’s a friend from cricket. Probably once every time we go into [regional town] we probably see him and that's in the off-season. We see him every weekend in the cricket season (Distance education male aged 15, Map Interview).

We use these courts when we play tennis. I'd like to use the ones near my house 'cause it's cheaper but the surface on this one [in the photo] is better 'cause the one over near my place there are some cracks in it, not exactly nice. Sometimes Max, Heidi and Ian come too so we'll just go there and play some tennis (Greenvalley High female aged 16, Photo Interview).

We go down to the river for a swim in summer, once a week if it's hot enough. Dad will take us or we walk. It's not far, about a twenty minute walk (Greenvalley High female aged 16, Photo Interview). 


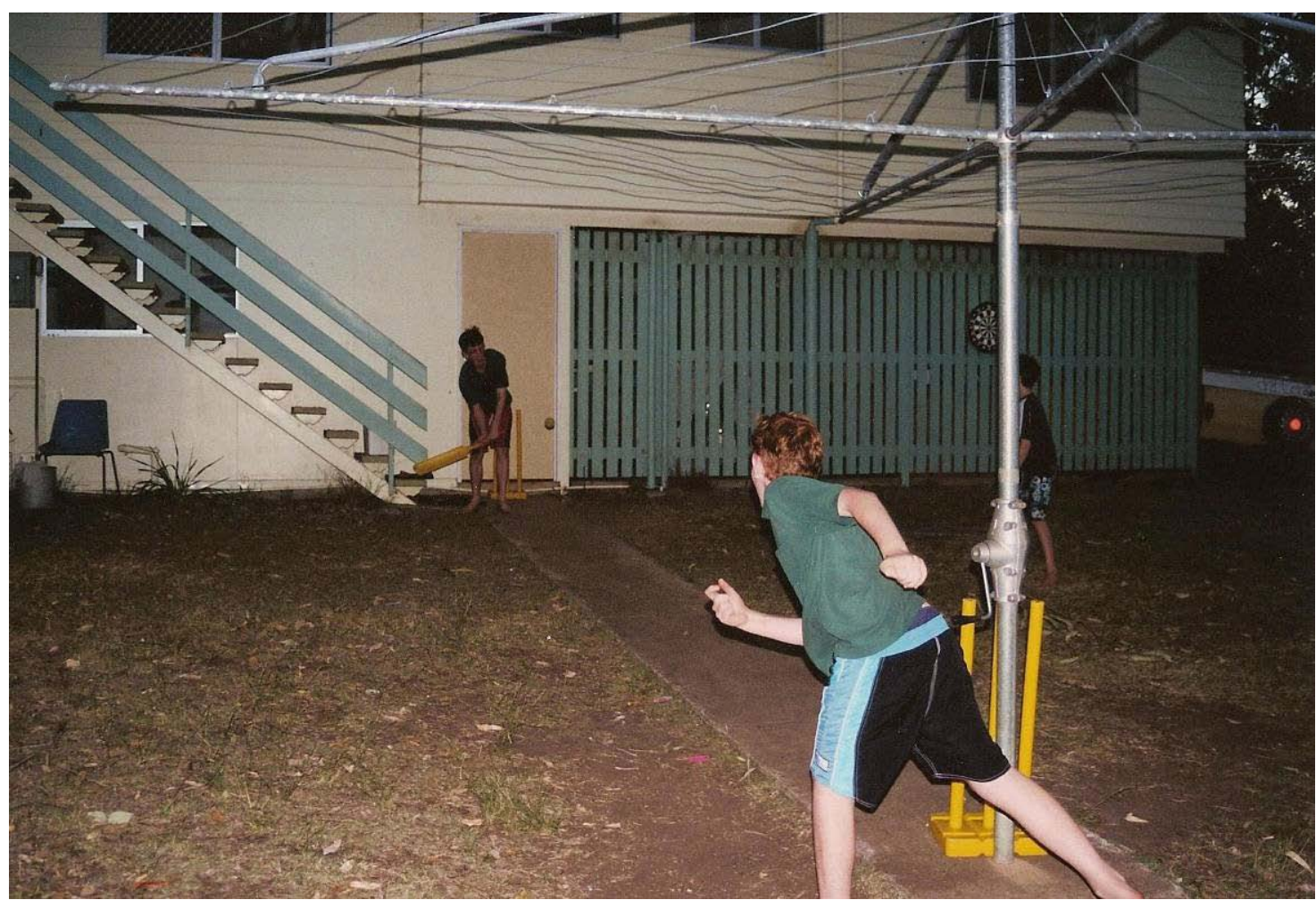

Figure 3. An example of a photo coded in both the family and sport/physical activity themes - male participant (Distance education, aged 12) playing backyard cricket with his siblings

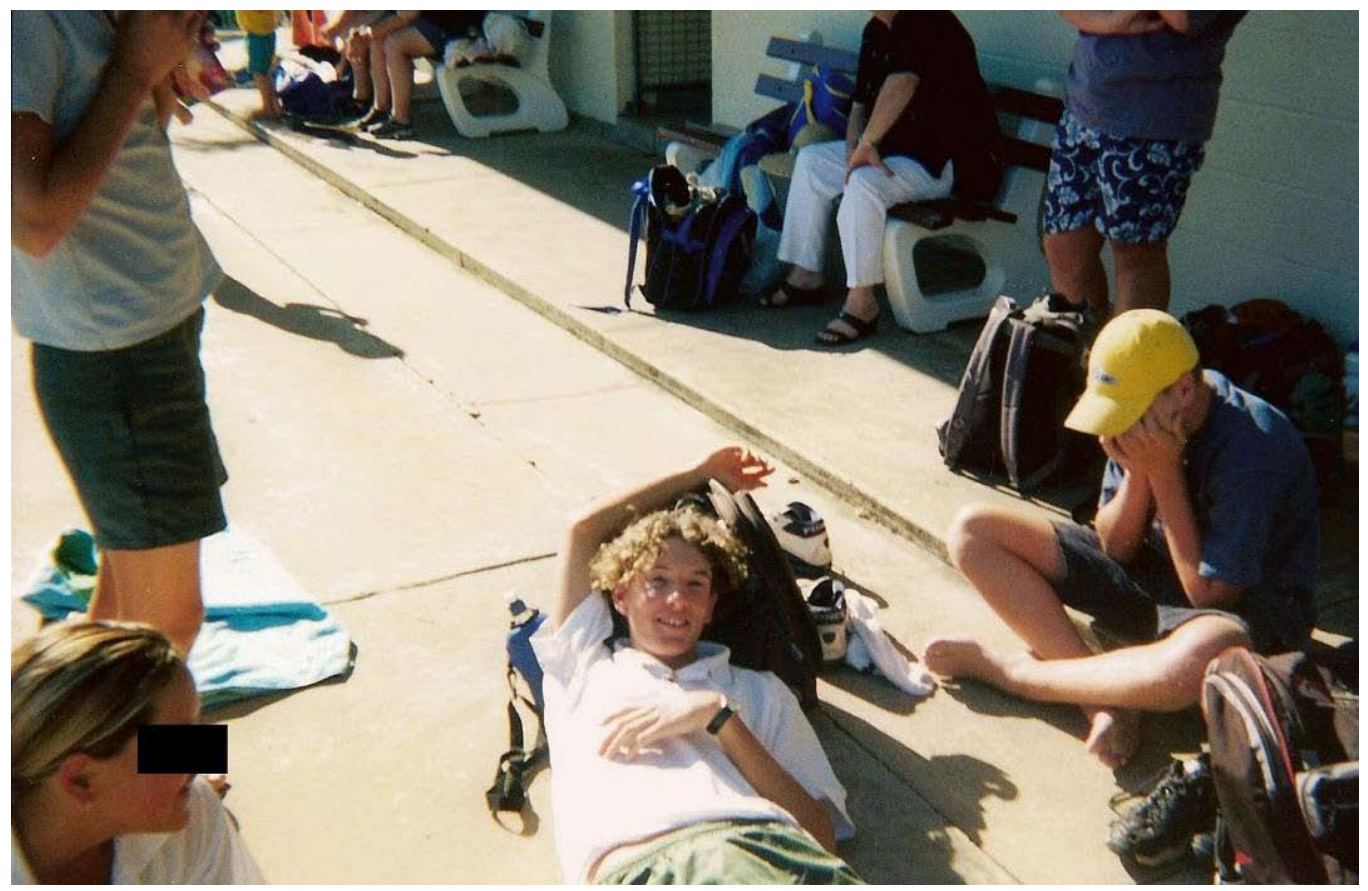

Figure 4. An example of a photo of friends in a sport context while not actually participating. Male participant (Greenvalley High aged 16) with his friends before swimming training. 
Using visual methods also illustrated the importance of grandparents and their role in the rural young people's participation in physical activities that would not have otherwise arisen.

My grandma just lives in the main street. I just walk to Grandma’s and ring up from there if my parents are late [picking me up from swimming] (Greenvalley High male, aged 16, Map Interview).

The same participant's map is in Figure 2 where his grandmother's house can be seen in relation to his own house and the swimming pool.

Grandma lives there as well so we go and visit her and we do a few [dressage] competitions there, like there's the [town] show every year and those kind of things and going to visit our horses that are there... (Distance education female, aged 14).

Usually in Christmas shoots they're usually more fun shoots [trap shooting]. So usually me, Dad, and Dad's two brothers and Grandad usually get in one squad and usually we throw cases at each other and play up and call out at each other when they're about to shoot and just muck up. Usually at competitions it's a big mental game though (Greenvalley High male aged 18, phone interview).

Indeed, the importance of the family in the rural context has been identified previously. Sarantakos (1998) claimed that despite the problems that rural families are reported to be faced with, they have been assessed as being as happy as, and as well functioning as, city families. Furthermore, Bourke (1998), in her study of the outlook of rural young people found that of an extensive list of items, that most students rated the family as very important compared to all other items. The current 
Rural young people and physical activity

research supports these findings along with those of Rossi and Wright (2002) who found that rural and remote families viewed sporting activities as providing opportunities for social involvement with peers.

Although physical activity emerged as a strong theme, it did not appear in all of the young people's maps and photos. The number of map sites and photographs related to physical activity was largely influenced by male participants, who tended to include multiple physical activity sites on their maps. The young men referred to both sports (e.g. golf, swimming club, cricket club, shooting competition, touch-football club) and recreational physical activities (e.g. bike riding, kayaking, table tennis) in their maps, photos and interviews. The young women’s depictions of physical activities were fewer compared to the young men’s, with some young women not referring to physical activities in their maps and photos at all. Of those young women who did, their physical activity tended to be recreational (e.g. tennis with friends, swimming in the river) rather than organised sports. One young woman was an exception as the majority of her photos were of herself participating in various dressage competitions. Of most significance here perhaps is the case of physical labour which was more often represented by the young men and spoken about in particularly gender nuanced ways. For example, certain “tough” forms labour were not performed by young women and for those young women who did engage in tougher forms of labour, they perceived themselves as looking masculine in such roles.

Previous research has demonstrated that traditional gender structures influence the sociospatial construction of place in rural settings (e.g. Dempsey, 1992; Giddings and Yarwood, 2005; Rye, 2006; Tucker and Matthews, 2001). This trend is consistent with other research which suggests that the nature of leisure and sports in rural settings tends to follow traditional gender structures (e.g. Dempsey, 1992; Henry, 1998) such that men’s physical activities take precedence over women’s and that women can be excluded from participation due to a hegemonic masculine culture. 
Rural young people and physical activity

Furthermore, Hunter and Riney-Kherberg (2002) acknowledge that studies of contemporary rural children have highlighted gendered notions of rural cultural environments. Absent from any previous research on the importance of family and friends and gender structures in rural young people's experiences with physical activities is a discussion of how these sociocultural aspects play a role in shaping rural young people's sense of place and how this impacts on their experiences in physical activities.

\section{A sense of place}

While previous research (Hume et al., 2005) has identified the importance of family and friends and physical activity and sport in the lives of young people as demonstrated in maps and photos, the current research goes beyond a thematic approach to explore how these themes are played out and the role of a sense of place. In addition to exploring the themes emerging from the maps and photographs, the use of visual data revealed how local spaces became places in the lives of the rural young people. A sense of place or belonging was apparent in most of the young people's maps in that they were able to depict numerous places of importance and their geographical relationship to each other. Some of these places covered a much greater area than others that focussed only on their local vicinity. For example, one distance education participant presented a very detailed map of his own property from two perspectives: one close-up of the area surrounding his house and the other an aerial view of the 42 thousand acre property (see Figure 5). This participant's social relationships were mostly restricted to his family and as such, he had a strong sense of belonging in the localised setting of their own property. No locations outside of the property were depicted on his map. In contrast, another distance education participant included reference to a number of places of importance along with others that he visited regularly up to 130 kilometres from his home (see Figure 6). 
Rural young people and physical activity
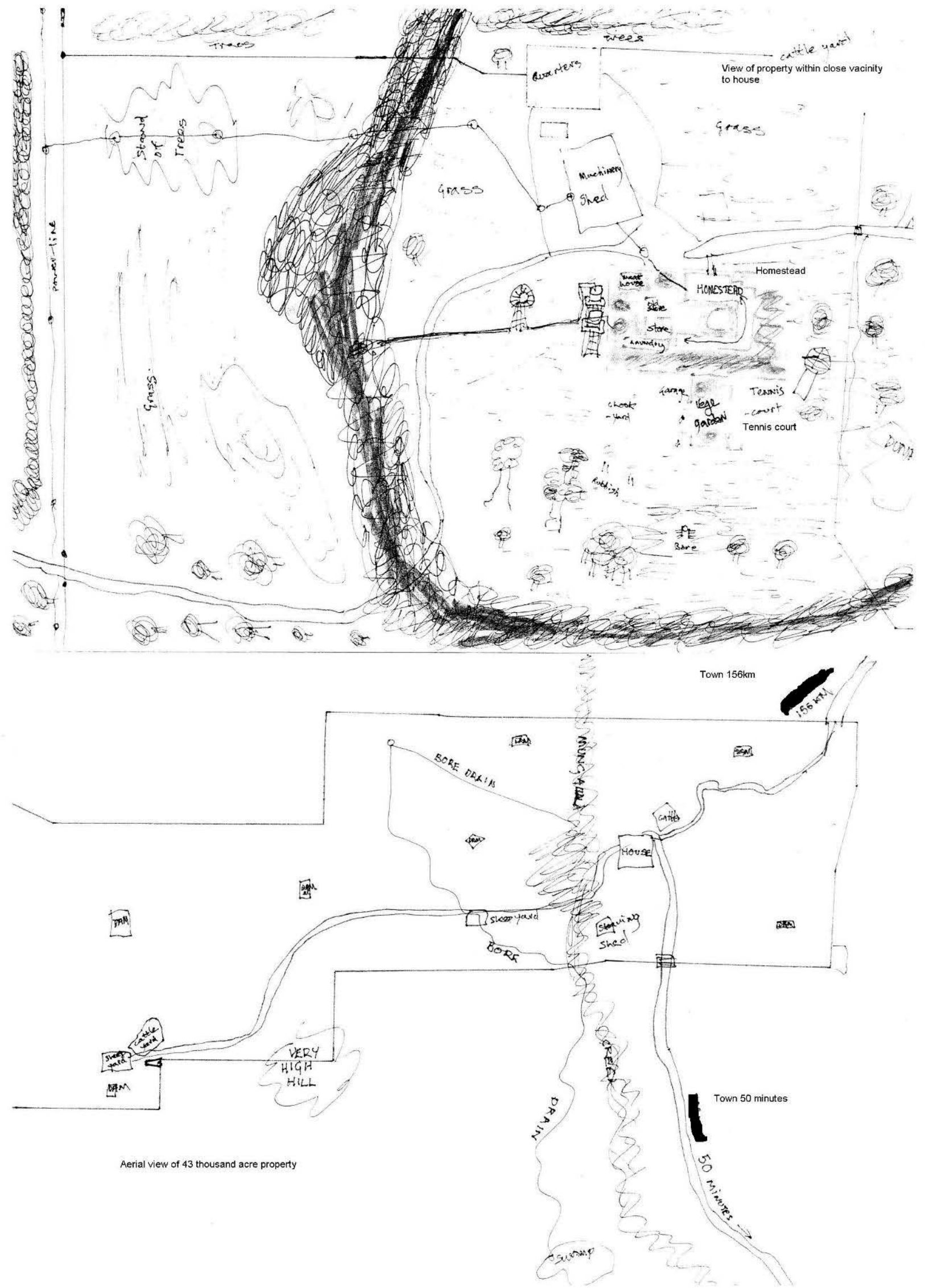

Figure 5. Map by male participant (Distance education, aged 13) showing in one half, the area close to the house and in the other half, an aerial view of the property. 


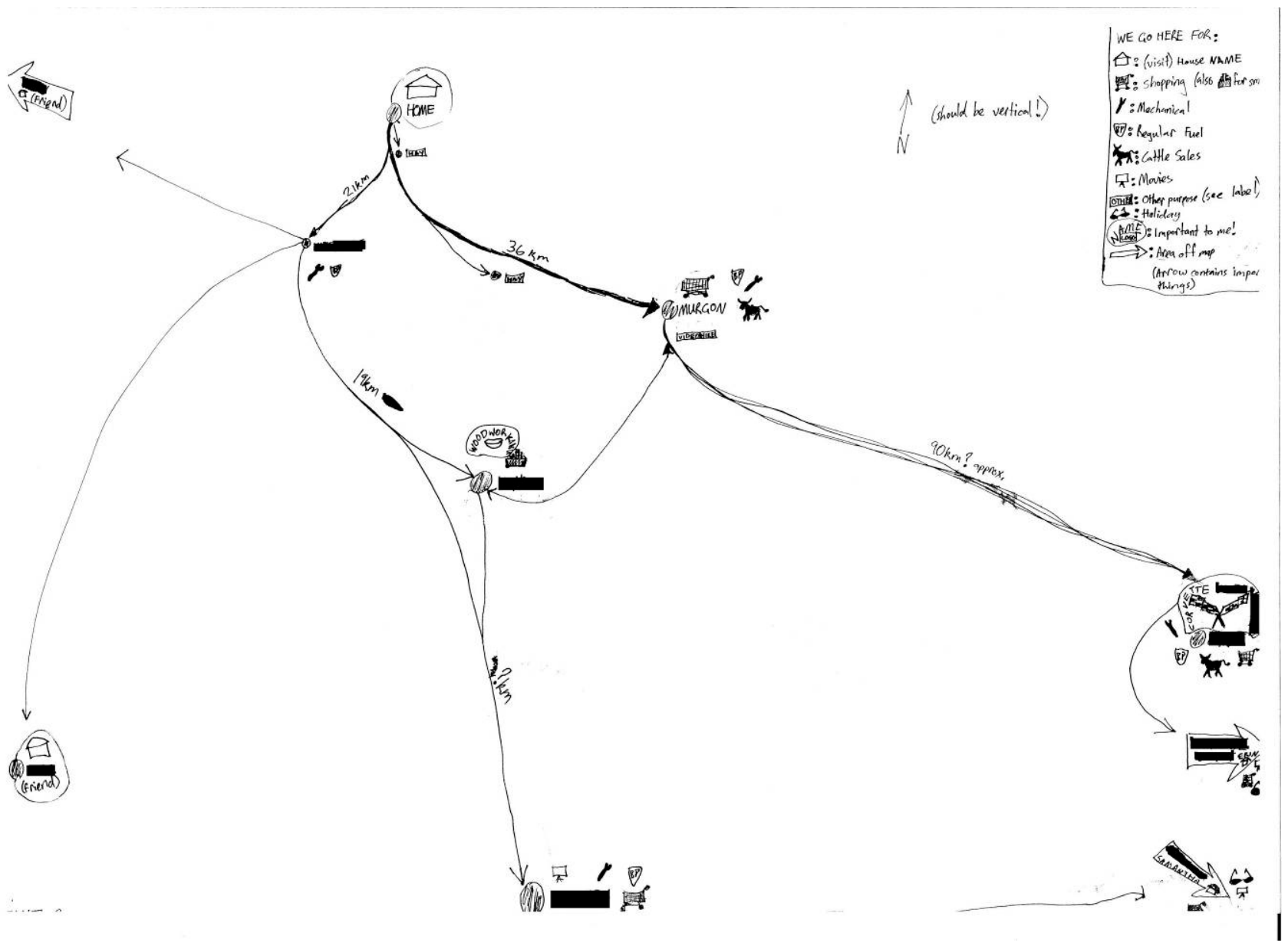

Figure 6. Map showing areas of importance to distance education participant (male, aged 13) up to $130 \mathrm{~km}$ from his home

Two young women who were mentioned in a previous section voiced difficulties in drawing maps of their local areas. Both of these young women had spaces of significance in three different locations but did not appear particularly connected to any place. Although one of these young women drew very detailed maps of the layout of the Greenvalley town centre and her local estate, she only noted one place of importance in each location (in addition to her own home in her local estate; see Figure 7). The other young woman's map resembled more a drawing of locations as she did not depict them in any spatial relationship (see Figure 8). She initially had trouble thinking of places to draw on her map and then found it difficult to represent them in relation to each other as the distances between them were too vast. 


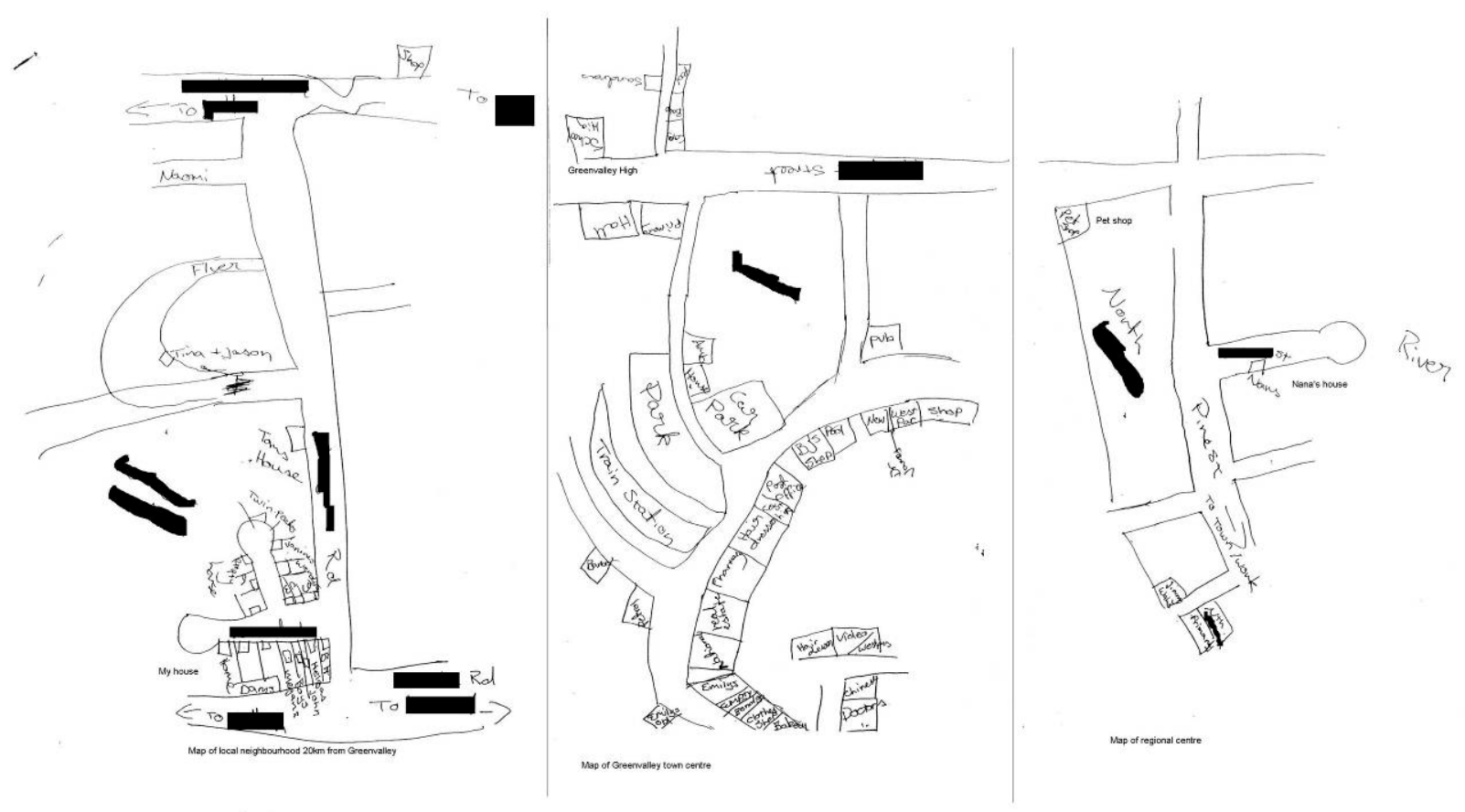

Figure 7. Map by female Greenvalley High participant (aged 18) depicting detailed layouts of her home neighborhood, Greenvalley town centre, and the closest regional centre. 

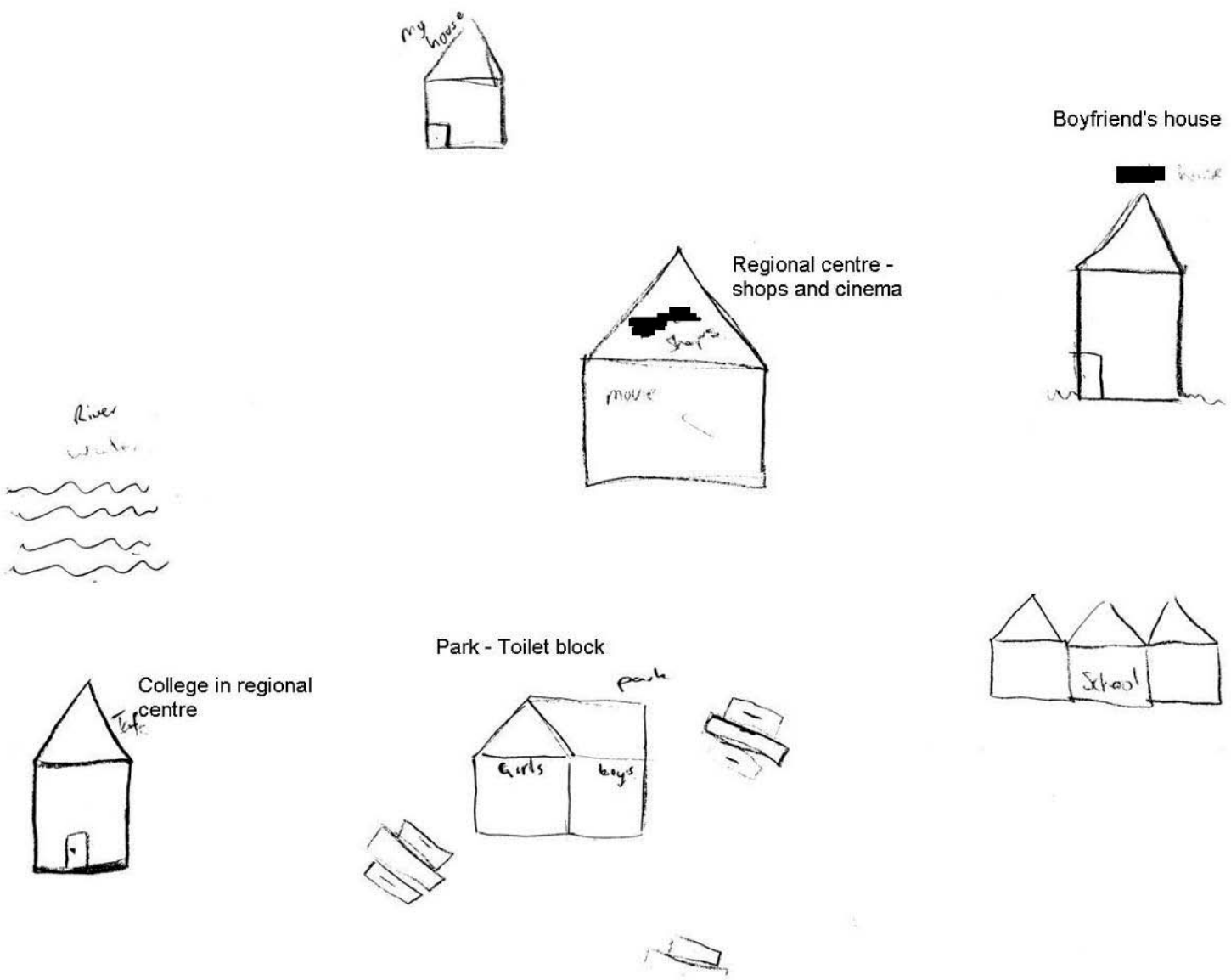

Figure 8. Map depicting locations of importance for Greenvalley High participant (female aged 16) without spatial reference.

The sense of place was most evident in the social relationships that the rural young people associated with spaces and activities in their environments. In the interviews, some of the young people expressed a profound closeness with their families. Friends and family were also discussed and depicted as co-participants in physical activity at a social level, rather than merely in supporting roles. The importance of these themes demonstrates the intense impact of the social on the rural young people’s sense of place and their engagements with physical activities.

In the particular case of the Greenvalley High participants, it was interesting to note the range of locations within the town that were accessed by the different young people. For example, only one 
Rural young people and physical activity

Greenvalley participant (male aged 16) included the swimming pool, recreation ground and golf course as locations of importance. Furthermore, while some participants included the Greenvalley town park on their maps, none of them indicated the basketball half-court, implying that this was not a place of importance, nor an opportunity to be physically active. Although one young woman drew the Palmdale (neighbouring town) skate park on her map, she considered it a social location for 'hanging out' rather than a place for being physically active. These findings emphasise Matthews and Limb’s (1999) claims that children's ways of seeing and place use differ from those of adults.

The diversity of locations on the maps highlights the discrepancy between availability and accessibility. There were clearly opportunities for competitive, social, and recreational physical activities within Greenvalley and one young man, due to his family circumstances (including social, economic, and cultural assets), was able to access these facilities. However, the other young people from Greenvalley did not utilise these facilities for various reasons and therefore, while the facilities were available, they were not readily accessed by the majority of the young people.

The young men were more likely to represent physical activities in general and in particular, sporting activities. A sense of place, including sociospatial understandings of the intersections of gender and rurality, appeared to shape these young people’s perceptions of, and participation in physical activities. It is important to note here that restrictions on participation in physical activity due to gender were not explicitly discussed by the rural young people themselves, although gender differences were evident in participation patterns and representations of sociospatial environments related to physical activity. Similarly, Rye (2006) in his research on Norwegian rural young people proposed that, 'rural youth do not very consciously reflect on rurality in abstract gender terms such as "masculinity” and "femininity" - gender is "done” in real life rather than being reflexively and explicitly “formulated”...' (p416). Gender roles, due to the division of labour, are firmly embedded 
Rural young people and physical activity

in rural communities as the activities most obviously linked to farm production and income are culturally understood to be men's activities, while women are recognised as helpers or supporters (Davidson, 2001). This hegemonic masculinity extends into leisure sites and popular rural physical activities such as camp drafting and bull riding (Campbell and Phillips, 1995; Henry, 1998). As Gard (2001) suggests, “...sport, masculinity and country life are concepts which come together easily” (p. 20). In this light we can say that an embedded gendered social order shapes rural places. As such, 'place' may be being performed in ways that are consistent with the accepted social structure within the young people’s rural environments. Performances of the appropriate gendered attributes afford the young people with certain embodied or material resources (capital) within their rural place or field. While it is proposed that the young people themselves would not reflect on their performances of gender as part of living in their rural contexts, from a reflexive standpoint it is suggested that within the rural places observed it would be beneficial for the rural young women not to participate in sports and to have a more family oriented outlook as that is the legitimised image of a rural woman. Conversely, the performance of the rural male was observed among the young men who engaged more heavily in sports, physical labour, and a wider range of recreational physical activities.

The young women however, were not the only ones whose access to certain activities was restricted. As also revealed by Tonts (2005), factors such as cultural knowledge and economic capital excluded some rural young people from accessing available sporting clubs and facilities such as swimming and golf. While these sports were clearly available in Greenvalley, they were only accessed and recorded in the map and photos of one male participant. As others (e.g. Giddings and Yarwood, 2005; Malone and Hasluck, 1998) have suggested, it is not only material facilities that influence rural young people's experiences of their environments. These findings are also consistent with those of Nairn et al. (2003) who found that young people’s cultural understandings influence their use of public space and therefore, presence of facilities is not an accurate depiction 
of actual access. Meanings of physical activity within the young people's lives indeed appeared to be tied to a sense of place. For some young women, the gendered culture of their rural setting (their place) impacted on their meanings of physical activity and hence, their participation. For some of the young people, economic and sociocultural factors impacted on their sense of place and participation in physical activities. For others, the strong sense of family and friendship which characterised their local places were mirrored in their meanings of, and associations with, physical activities. The use of visual methodologies enabled an exploration into how social factors such as friends and family and wider social structures such as gender norms contribute to a sense of place for rural young people which is played out in the meanings they attribute to physical activities and physical activity locations. Therefore, while the themes of family and friends, physical activity, and gender were not particularly surprising given previous research, it was how these structures shaped the rural young people’s sense of place that differentiated their experiences.

\section{Conclusion}

The purpose of this research was to explore rural young people’s perceptions of their local environments, both social and geographical in relation to their engagements with physical activities through the use of visual methodologies. The maps and photos along with interviews were used to understand the place and meaning of physical activity for these young people. With rural Australian young people often depicted from the outside as a group in crisis, with poorer health and lower physical activity and sport opportunities, it is important to explore from the young people's perspectives, how these issues play out in their own lives.

Findings suggested that while fewer formal physical activity options may be available in rural communities, most of the young people engaged in some form of physical activity, at least at a 
Rural young people and physical activity

recreational level. Perhaps, as Gordon and Caltabiano (1996) reported, rural young people learn to 'make do’ with available leisure options. As such, this would suggest that as Giddings and Yarwood (2005) propose, rural young people’s status as ‘marginalised' in terms of physical activity may not be collectively held by the young people themselves attesting to Leyshon's (2002) claim that 'marginality is a social, cultural and spatial construction not universally experienced by all rural youth' (p.180). Indeed, the notion of 'performativity of place' was raised, particularly in terms of embedded traditional gender roles in rural places. By performing gender (and indeed other dominant ways of being) within the legitimised boundaries of the rural places young people are gaining capital or social currency within their places or contexts. As such, what might be observed from the outside (particularly by city-dwelling academics and government policy makers) as marginalisation due to lack of facilities and opportunities, rural young people are shaped by, and therefore comfortable within their own "particular places of the possible” (Bourdieu, 1998, p. 13). Thus, their participation in physical activities is consistent with other practices of becoming shaped by their rural places.

A contribution of the current research concerns using visual methods as a tool for collecting data. Along with the themes and commonalities, the visual data highlighted the diversity of experience within the rural cohort. Furthermore visual methods may be particularly useful for young people, as they can help to maintain the participants' interest in the research. Most of the rural young people enjoyed using the cameras and were interested in how their photos had turned out. They also found the photos a valuable way of depicting their lives as they would often say in the photo interview, 'I took this photo to show you...'. The maps were useful in providing some spatial data and exploring the social and spatial elements of place, and while it did not suit all of the participants, it did allow some to express their views in a format other than interviews. The maps also allowed for an exploration of social and recreational space, which highlighted the rural young people’s sense of place, not revealed in traditional interview contexts and specifically how social structures involving 
Rural young people and physical activity

family, friends and gender were represented in relation to physical activities. The snapshots of young people’s lives as reported in this paper are useful in exploring how diversity is played out and experienced rural young people's lives. The small sample size allowed for in-depth explorations emphasising that rural young people are not a homogenous group and different geographical and social locations shape young people’s sense of place and participation in physical activities in diverse ways. Whilst previous research has explored rural young people’s sense of place it has not related this to rural young people’s experiences in physical activities. Indeed, in depth qualitative research involving visual methodologies to explore sense of place related to physical activity is particularly rare.

While the current research focussed on in-depth case studies with a small sample, it highlights important issues for investigation on a larger scale. Specifically, it raises questions regarding the measurement of physical activity, and the generation of physical activity promotion initiatives and policy. The prevalence of recreational physical activity for the rural young people in this cohort calls attention to a potential flaw in self-report, population physical activity measurement tools which tend to focus on organised or at least intentional forms of physical activity and often identify rural young people as less active and having restricted access to sporting facilities. The types of physical activities that are common amongst rural young people may not be captured by population measurement tools. It was also demonstrated that it is not material facilities alone that contribute to rural young people's physical activity patterns and that the presence of facilities is not an accurate depiction of actual access. Therefore, similar to Giddings and Yarwood's (2005) suggestion, policies and initiatives for rural physical activity promotion should be planned on a social and cultural, rather than purely physical, basis. Examining environments from young people's own perspectives allows us to see what environments 'afford' young people which may be different to adult perceptions (Tapsell, Tunstall, House, Whomsley and Macnaghten, 2001). Furthermore, it appears all too easy as outsiders to label rural young people as the 'other' or marginalised in terms 
Rural young people and physical activity

of physical activity opportunities however, when 'looking up' from their own perspectives, we can see that they are physically active in ways that may not be officially measured and also that they appear not to reflect on the impact of an embedded rural gender structure. The use of visual methods to examine participation in, and perceptions of physical activity among rural young people has been useful in contributing to this process and adding to the current knowledge base. Research of this kind on a larger scale could contribute to the generation of more sustainable and equitable means of promoting and providing physical activity for both urban and rural young people. 


\section{References}

Australian Bureau of Statistics, 2003. Children's Participation in Cultural and Leisure Activities. Australian Bureau of Statistics [online]. Australian Bureau of Statistics. Available from: www.abs.gov.au [Accessed 12 December 2004].

Australian Bureau of Statistics, 2000. Children's Participation in Cultural and Leisure Activities. Australian Bureau of Statistics. Available from: www.abs.gov.au [Accessed 13 May 2001]. Bourdieu, P. (1998) Practical reason: On the theory of action. California: Stanford University Press.

Bourke, L., 1998. Outlook of rural secondary students. In: S. Sarantakos, ed. Quality of Life in Rural Australia. Wagga Wagga, New South Wales: Centre for Rural Social Research, Charles Sturt University, 50-57.

Campbell, H. and Phillips, E. (1995) Masculine hegemony and leisure sites in rural New Zealand and Australia. In Share, P. (ed.) Communication and culture in rural areas. Wagga Wagga, Australia: Centre for Rural Social Research, Charles Sturt University.

Clark, C.D., 1999. The autodriven interview: A photographic viewfinder into children's experience. Visual Sociology, 14, 39-50.

Dempsey, K., 1992. A Man's Town: Inequality Between Women and Men in Rural Australia. New York: Oxford University Press.

Gard, M. (2001) Sport, physical education and country towns: diverse enough?, Education in Rural Australia, 11, 2, 19-26.

Giddings, R. and Yarwood, R., 2005. Growing up, going out and growing out of the countryside: Childhood experiences in rural England. Children's Geographies, 3, 101-114.

Gordon, W.R. and Caltabiano, M.L., 1996. Youth leisure experiences in rural and urban North Queensland. Australian Leisure, 7, 37-42. 
Rural young people and physical activity

Henry, J., 1998. Bullriding into manhood. In: C. Hickey, L. Fitzclarence, and R. Matthews eds. Where the Boys Are: Masculinity, Sport and Education. Geelong, Victoria: Deakin Centre for Education and Change, 97-108.

Hume, C., Salmon, J., and Ball, K., 2005. Children's perceptions of their home and neighborhood environments, and their association with objectively measured physical activity: A qualitative and quantitative study. Health Education Research, 20, 1-13.

Hunter, K. and Riney-Kehrberg, P., 2002. Rural daughters in Australia, New Zealand and the United States: an historical perspective. Journal of Rural Studies, 18, 135-143.

Leyshon, M., 2002. On being 'in the field': Practice, progress and problems in research with young people in rural areas. Journal of Rural Studies, 18, 179-191.

Malone, J. and Hasluck, L., 1998. Geographies of exclusion: Young people's perceptions and use of public space. Family Matters, 49, 20-26.

Matthews, H. and Limb, M., 1999. Defining an agenda for the geography of children: review and prospect. Progress in Human Geography, 23, 61-90.

Morrow, V., 2001. Using qualitative methods to elicit young people's perspectives on their environments: Some ideas for community health initiatives. Health Education Research, 16, 255-268.

Mugford, S., 2001. The Status of Sport in Rural and Regional Australia: Literature, Research and Policy Options. Canberra, Australia : Sport Industry Australia.

Mummery, W.K., Schofield, G.M., Abt, G., and Soper, L., 2000. Correlates of adolescent physical activity in regional Australia: Results from the Central Queensland Adolescent Physical Activity and Nutrition Study. Proceedings of the AIESEP World Sport Science Congress. Rockhampton, Australia Central Queensland University, 3-14.

Nairn, K., Panelli, R. and McCormack, J., 2003. Destabalizing Dualisms: Young people's experiences of rural and urban environments. Childhood, 10, 9-42. 
Orellana, M.F., 1999. Space and place in an urban landscape: Learning from children's views of their social worlds. Visual Sociology, 14, 73-89.

Ross, N.J. 2007. 'My journey to school...': Foregrounding the meaning of school journeys and children's engagements and interactions in their everyday localities. Children's Geographies, 5 (4), 373-391.

Rossi, T. and Wright, J., 2002. Children's physical activity, health and physical education in isolated rural contexts: The views of parent educators in Queensland. Education in Rural Australia, 12, 2-7.

Rye, J.F., 2006. Rural youths' images of the rural. Journal of Rural Studies, 22, 409-421.

Saranatkos, S., 1998. Families in the city and on the farm. In: S. Sarantakos, ed. Quality of Life in Rural Australia. Wagga Wagga, New South Wales: Centre for Rural Social Research, Charles Sturt University, 93-103.

Savage, M.P. and Scott, L.B., 1998. Physical activity and rural middle school adolescents. Journal of Youth and Adolescence, 27, 245-253.

Stokowski, P.A., 2002. Languages of place and discourses of power: Constructing new senses of place. Journal of Leisure Research, 34, 368-382.

Tapsell, S., Tunstall, S., House, M., Whomsley, J. and Macnaghten, P., 2001. Growing up with rivers? Rivers in London children’s worlds. Area ,33, 177-189.

Tonts, M. (2005). Competitive sport and social capital in rural Australia. Journal of Rural Studies, 21, 137-149.

Tucker, F. 2003. Sameness or difference? Exploring girls' use of recreational spaces. Children's Geographies, 1 (1), 111-124.

Tucker, F. and Matthews, H., 2001. 'They don't like girls hanging around there': conflicts over recreational space in rural Northamptonshire. Area, 33, 161-168.

Vanderbeck, R.M., Morse Dunkley, C., 2003. Young people's narratives of rural-urban difference. Children's Geographies 1, 241-259. 
Rural young people and physical activity

Notes

1. Pseudonyms for names of participants, schools, and locations have been used to protect anonymity. 